\title{
Assessment of Vasculopathy using Doppler Ultrasound in Patients with Diabetic Foot: An Observational Study
}

\author{
S. Fareed UI Hameed ${ }^{1}$, Karuppasamy $\mathrm{P}^{2}$, Habeeb Mohammed ${ }^{3}$ \\ ${ }^{1}$ Assistant Professor, Department of General Surgery, ${ }^{2}$ Associate Professor, Department Of General Surgery, ${ }^{3}$ Professor \\ and HOD, Department of General Surgery, Melmaruvathur Adhiparasakthi Institute of Medical Sciences and Research, \\ Melmaruvathur, Kancheepuram, District Tamilnadu, India
}

Corresponding author: Dr. Karuppasamy P, No. D-6 Doctors Quarters, Melmaruvathur, Tamil Nadu, India

DOI: http://dx.doi.org/10.21276/ijcmsr.2019.4.4.22

How to cite this article: S. Fareed Ul Hameed, Karuppasamy P, Habeeb Mohammed. Assessment of vasculopathy using doppler ultrasound in patients with diabetic foot: an observational study. International Journal of Contemporary Medicine Surgery and Radiology. 2019;4(4):D91-D95.

\section{A B S T R A C T}

Introduction: Diabetes mellitus with its associated complications is a major cause of morbidity and mortality worldwide. The development and progression of chronic complications of diabetes are closely related to glycaemic control. Diabetic foot is one of the most frequent reasons for hospitalization in a surgical ward; its complications include abscess formation, cellulitis, ulceration and gangrene. Hence, the aim of this study was to correlate the severity of diabetic foot lesions by Wagner grading with Ankle Brachial Index in diabetic patients on a Doppler-based evaluation.

Material and methods: In this observational study, about 50 cases of "Diabetic Foot" were studied from May 2011 to May 2013 admitted in Krishna Institute of Medical Sciences, Karad. Diabetic patients who were 18 years or above irrespective of the type of diabetes and gender with suspected peripheral vascular insufficiency or complaints of numbness, discoloration of periphery or ulceration were included in this study. Patients with history of arterial graft procedures and present with blisters, cellulitis, abscess, gangrene lesions was present other than the diabetes were not included in the study.

Results: The most common mode of presentation was ulcer in 19 cases followed by 14 cases of Cellulitis based on the mode of clinical presentation. In the present study, about 23 patients had hypertension followed by 8 cases of COPD and 5 cases of IHD. Maximum number cases (15) were seen in Grade III Wagner's Grading The maximum number of patients (14) had moderate ankle brachial index.

Conclusion: It was found in the present study that vascular insufficiency was present in $62 \%$ of the patients with dorsalispaedis being the commonest site of involvement. In patients exhibiting doppler-documented vasculopathy, the mean duration of disease was almost a decade. Hence, colour doppler sonography can locate the site and extent of stenosis/occlusion accurately.

Keywords: Vasculopathy, Doppler Ultrasound, Diabetic Foot, Observational Study

\section{INTRODUCTION}

Diabetes mellitus is a 'silent killer' disease with a long and fascinating history, which dates as far back as 1600 years before Christ. The first reference one can have regarding diabetes is from Egyptian compilation Ebers Papyrus (1500 $\mathrm{BC}$ ). The word diabetes was used by Areatasus of Cappodoila, a Roman Physician in 2nd century A.D. He described the disease as melting down of flesh and limbs into urine. The Greeks, who knew about its prominent manifestation of polyurea, named the disease, diabetes (passing like a fountain through a siphon). The Indian physician Sushruta described the disease as "Madhu Meha" (passing honey urine) in 400 B.C. The human foot is a mechanical marvel; it consists of 26 Bones, 29 joints, 42 muscles and a multitude of tendons and ligaments. ${ }^{1,2}$

In developing countries, diabetes mellitus has a higher prevalence rate and is a common pathological condition. Due to the acute and long-term complications secondary to the involvement of micro and macro vasculature along with the progression of the natural history of disease, diabetes mellitus has a marked impact on the quality of life. ${ }^{3}$

The association between foot ulceration, neuropathy and vascular disease was first recognized by Pryce in 1887 . Diabetic neuropathy was first described by Marshal in 1864 . Until Jordan (1936), it was believed that neuropathy was due to vascular disease but he showed that, not all his patients of trophic ulcers had atherosclerosis. Oakley (1956) classified foot problems as infection, ischemia followed by neuropathy and combination. Gabby and O'sullivan described sorbitol pathway in $1968.4,5$

Peripheral arterial disease (PAD) is a condition very frequently seen among individuals with diabetes which is characterized by occlusive changes in the lower extremities arteries. It has observed that peripheral ischemic event rates are higher in diabetic individuals and even in atherosclerotic populations with PAD than in non-diabetic. It is major contributory factor to diabetic foot ulceration and gangrene 
leading to lower-extremity amputation in diabetes mellitus. So, spectral doppler (Duplex) sonography is well-accepted and recognized as a non-invasive imaging modality to be used as a diagnostic test for detecting and grading the presence and severity of arterial disease. .,7 $^{6}$

In order to determine the subset of patients that may be at a high risk of subsequent myocardial infarction or stroke, diagnosis of $\mathrm{PAD}$ in diabetic patients is of great clinical significance irrespective of the presence or absence of symptoms of PAD. Thus, regular screening is important as a part of aggressive management to decrease the impact of comorbidities on the affected person. ${ }^{8}$

In terms of stenosis, the evaluation of the state of peripheral arteries of the lower limb, and its association with patient symptomatology are found to be important. This way it can act as a basis for regular follow up of the cases at the risk of arterial disease and early intervention to salvage the limb if vascular insufficiency is detected at an early stage. ${ }^{9}$

The presence of symmetric distal polyneuropathy, encompassing motor, sensory and autonomic involvement is the most important factor in the development of diabetic foot ulcers. Neuropathy and ischemia are the two commonest complications seen in diabetes mellitus. They are the primary underlying risk factors for the development of foot ulcers and their complications. It has been observed that one-third of diabetic foot ulcers have mixed ischemic etiology and neuropathy. ${ }^{10,11}$

In the formation of diabetic foot ulcers, although neuropathy and ischemia are the primary predisposing factors but an initiating factor, for example, physical or mechanical stress is required for the development of ulcer. Furthermore, to increase the risk of ulceration, diabetes mellitus also raises the risk of infection by impairing the body's ability to eliminate bacteria. Ischemic ulcers develop as a result of low perfusion pressure and inadequate blood supply in the foot, whereas neuropathic ulcers result from higher pressures in a foot with adequate blood supply but low protective sensation. ${ }^{12}$

Doppler ultrasound is non-invasive based on objective measurements of the spectrum and velocity of flow in arteries that can be monitored serial-wise. From previous literature, it was found that local studies have not evaluated Doppler scanning as a means of evaluating vascular complications in diabetics. ${ }^{13}$ Therefore, the aim of the present study was to correlate the severity of diabetic foot lesions by Wagner grading with Ankle Brachial Index in diabetic patients on a Doppler-based evaluation.

\section{MATERIAL AND METHODS}

The present study was an observational prospective study which was carried out in the Krishna, Karad Hospital during the period of May 2011 to May 2013. About 50 cases of diabetic foot lesions admitted in were examined prospectively. Adult diabetic patients (aged 18 years or above) irrespective of type of diabetes and gender with suspected peripheral vascular insufficiency or complaints of numbness, discoloration of periphery or ulceration. Patients who had undergone arterial graft procedures and those present with blisters, cellulitis, abscess, gangrene lesions occurring other than diabetes were not included in the study. Also, gestational diabetic patients were excluded from this study. All patients were evaluated by taking detailed history; clinical examination and necessary investigation were taken along with Doppler study according to case proforma. Categorization and tabulation of the data was done according to the observation section.

\section{Diabetic foot ${ }^{14}$}

\section{Classification}

Although various classifications have been suggested, there is, as yet, no universally acceptable classification. The diabetic foot is classified, as per the underlying etiology, into

1. Neuropathic foot (Neuropathy is dominant)

2. Neuroischemic foot (Occlusive vascular disease is dominant)

The presence of infection is of paramount importance as it alters the prognosis adversely and hastens the progress towards a limb amputation. It is therefore extremely important to include its presence or absence in any classification of the diabetic foot.

\section{Suggested Classification \\ Neuropathic foot \\ a. with infection \\ b. without infection}

\section{Neuroischemic foot}

a. with infection

b. without infection

\section{STATISTICAL ANALYSIS}

The data was entered into the Microsoft excel sheet and was analyzed using SPSS software version 21. Descriptive statistics was used in the form of percentages and frequency distribution. The data is presented in the form of tables.t

\section{RESULTS}

In the present study, about 50 patients were studied in this series between age groups of 21-90 years. Maximum incidence was seen in the age group of 51-60 yrs. Youngest patient was found to be 27 years and oldest was 82 years (Table 1). Out of these 50 patients, 35 (70\%) were males and 15(30\%) were females (Table 2). There was marked male preponderance in this study. Majority of the patients $31(61 \%)$ gave history of

\begin{tabular}{|l|c|c|}
\hline Age in years & No. of cases & Percentage \\
\hline $21-30$ & 1 & $2 \%$ \\
\hline $31-40$ & 2 & $4 \%$ \\
\hline $41-50$ & 9 & $18 \%$ \\
\hline $51-60$ & 17 & $34 \%$ \\
\hline $61-70$ & 14 & $28 \%$ \\
\hline $71-80$ & 6 & $12 \%$ \\
\hline $81-90$ & 1 & $2 \%$ \\
\hline \multicolumn{2}{|c|}{ Table-1: shows the distribution of data based on the age } \\
\multicolumn{2}{|c|}{ among study subjects } \\
\hline
\end{tabular}

\begin{tabular}{|l|c|c|}
\hline Gender & No. of Cases & Percentage \\
\hline Male & 35 & $70 \%$ \\
\hline Female & 15 & $30 \%$ \\
\hline Table-2: Shows the distribution of data based on the gender \\
among study subjects \\
\hline
\end{tabular}


trauma as predisposing factor while in remaining patients there was no history of trauma (Table 3 ). Maximum patients i.e. $21(61 \%)$ had diabetes duration between 1-5 years (Table 4). Most common affected limb was found in left side with 23 patients and 20 patients on right side. Bilateral lower limb
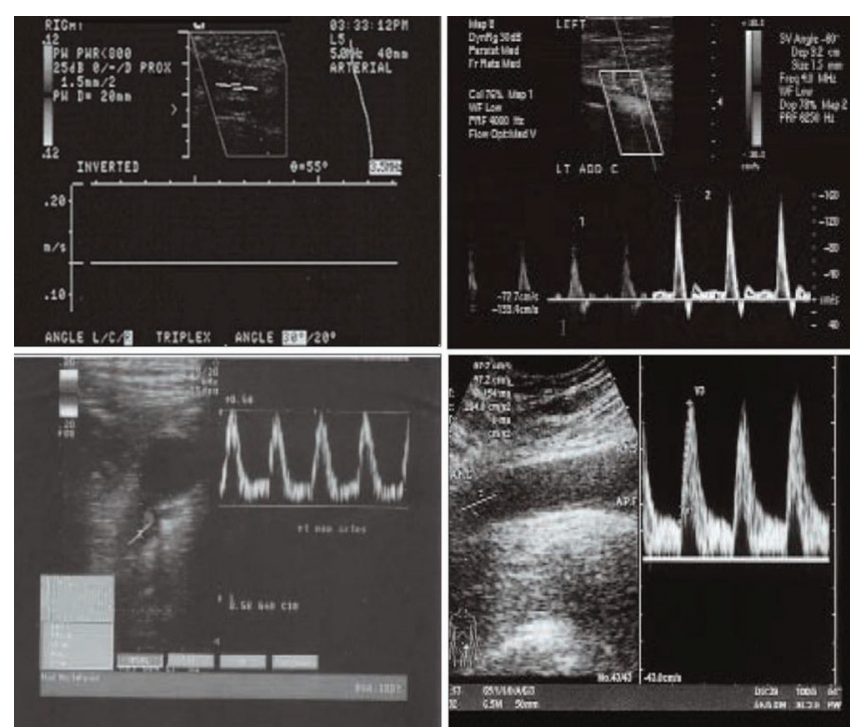

Figure-1: Shows the Doppler scan showing moderate ischemia with spectral broadening and biphasic flow

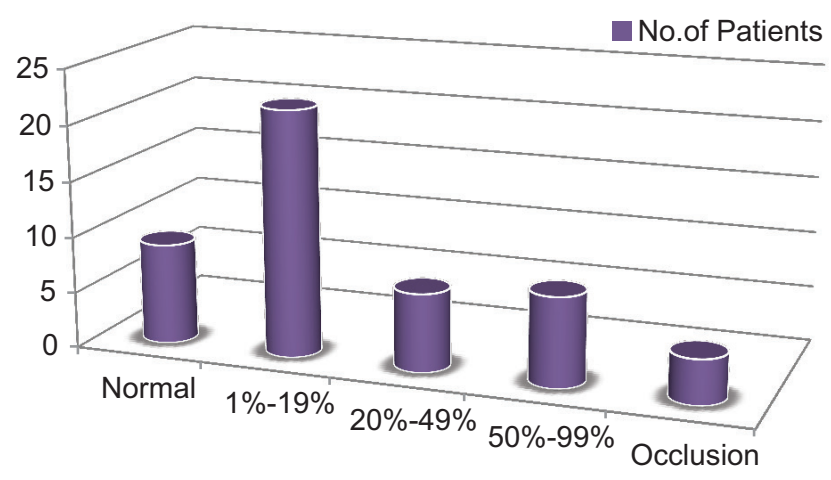

Graph-1: Shows the percentage of stenosis among the study subjects

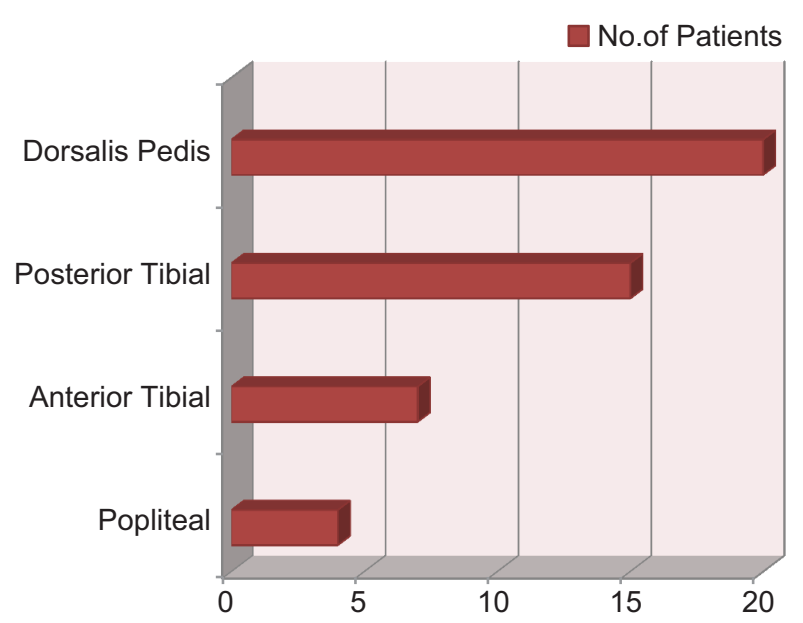

Graph-2: Shows the absence of arterial pulsations among the study subjects

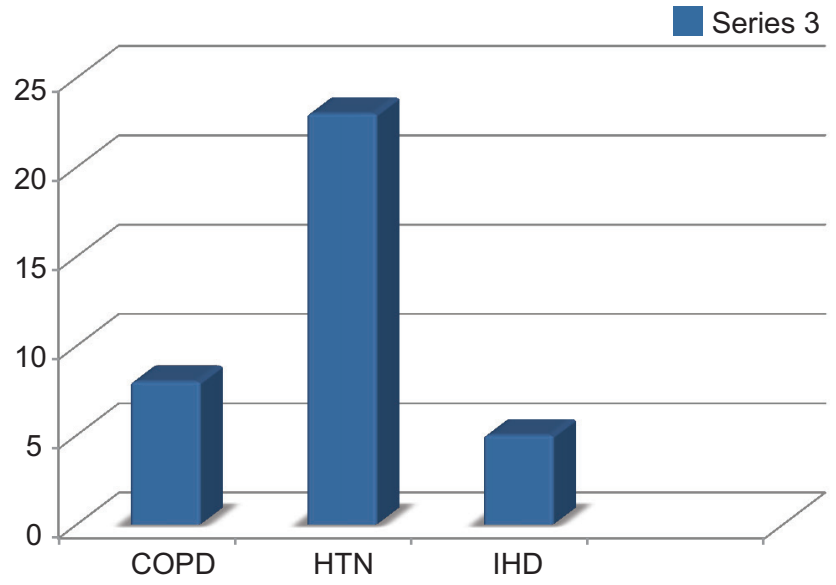

Graph-3: Shows the co-morbidities among the study subjects

\begin{tabular}{|l|c|}
\hline History of Trauma & No. of patients \\
\hline Yes & 31 \\
\hline No & 19 \\
\hline Table-3: Shows the distribution of data based on the history of \\
trauma among study subjects
\end{tabular}

\begin{tabular}{|l|c|}
\hline Diabetic Duration (in years) & No. of Cases \\
\hline $1-5$ years & 21 \\
\hline $6-10$ years & 20 \\
\hline $11-15$ years & 6 \\
\hline $16-20$ years & 1 \\
\hline $21-25$ years & 2 \\
\hline $\begin{array}{l}\text { Table-4: Shows the distribution of data based on the duration } \\
\text { of diabetes among study subjects }\end{array}$ \\
\hline
\end{tabular}

\begin{tabular}{|l|c|}
\hline Side affected & No. of patients \\
\hline Right & 20 \\
\hline Left & 23 \\
\hline Bilateral & 7 \\
\hline \multicolumn{2}{|c|}{ Table-5: Shows the distribution of data based on the affected } \\
side among study subjects
\end{tabular}

\begin{tabular}{|l|c|}
\hline Type of Lesion & No. of Cases \\
\hline Cellulitis & 14 \\
\hline Abscess & 10 \\
\hline Ulcer & 19 \\
\hline Gangrene & 7 \\
\hline \multicolumn{2}{|c|}{ Table-6: Shows the distribution of data based on the type of } \\
lesion among study subjects \\
\hline
\end{tabular}

\begin{tabular}{|l|c|}
\hline Wagner 's Grading & No. of Cases \\
\hline Grade 0 & 4 \\
\hline Grade 1 & 9 \\
\hline Grade 2 & 11 \\
\hline Grade 3 & 15 \\
\hline Grade 4 & 7 \\
\hline Grade 5 & 4 \\
\hline Table-7: Shows the distribution of data based on Wagner's \\
grading among study subjects \\
\hline
\end{tabular}




\begin{tabular}{|l|c|}
\hline Ankle Brachial Index & No. of Patients \\
\hline Normal $(0.9-1.3)$ & 13 \\
\hline Mild $(0.8-0.9)$ & 12 \\
\hline Moderate $(0.5-0.8)$ & 14 \\
\hline Severe $(<0.5)$ & 7 \\
\hline Critical $(<0.3)$ & 4 \\
\hline $\begin{array}{c}\text { Table-8: Shows the distribution of data based on Ankle brachi- } \\
\text { al index among study subjects }\end{array}$ \\
\hline
\end{tabular}

\begin{tabular}{|l|c|}
\hline Doppler Study & No. of Cases \\
\hline Normal & 9 \\
\hline Atherosclerosis with Normal flow & 22 \\
\hline Atherosclerosis with Reduced flow & 19 \\
\hline $\begin{array}{c}\text { Table-9: Shows the distribution of data based on using Dop- } \\
\text { pler findings among study subjects }\end{array}$ \\
\hline
\end{tabular}

\begin{tabular}{|l|c|}
\hline Diameter Reduction & No. of Patients \\
\hline Normal & 9 \\
\hline $1 \%-19 \%$ & 22 \\
\hline $20 \%-49 \%$ & 7 \\
\hline $50 \%-99 \%$ & 8 \\
\hline Occlusion & 4 \\
\hline Table-10: Shows the distribution of data based on diameter \\
reduction among study subjects
\end{tabular}

was affected in 7 patients (Table 5).

The most common mode of presentation was ulcer in 19 cases followed by 14 cases of Cellulitis based on the mode of clinical presentation (Table 6). In the present study, about 23 patients had hypertension followed by 8 cases of COPD and 5 cases of IHD. Maximum number cases 15 were seen in Grade III Wagner's Grading (Table 7). The maximum number of patients 14 had moderate ankle brachial index. About 4 patients showed critical ankle brachial index (Table 8). Arterial pulsations was absent in number of patients. Maximum number of subjects i.e. about 22 (44\%) showed atherosclerosis with normal flow using Doppler method. Most number of patients 22 had mild stenosis and complete occlusion was seen in 4 patients (Table 9). About 22 patients had diameter reduction of 1\%-19\% (Table 10).

It was found that about 22 patients had mild stenosis and complete occlusion was seen in 4 patients (Graph 1). The most common absent pulsation was found to be in Dorsalispedis artery in 20 patients and least common with popliteal artery in 4 patients (Graph 2). In the present study, 23 patients had hypertension followed by 8 cases of COPD (chronic obstructive pulmonary disease) and 5 cases of ischemic heart disease (Graph 3).

\section{DISCUSSION}

The association between diabetes and symptoms in the limbs was first recognized by John Rollo. Exact pathogenesis of diabetic vascular disease is still unknown. Recent investigations have implicated role of endothelial injury, platelets, monocytes, prostaglandins, lipoproteins, hyperglycemia in etiopathogenesis of diabetic vasculopathy. In a study done by Crisband et al, the author supported the response to injury hypothesis. Following vessel injury, fibrous flake evolves as a result of proliferation of arterial smooth muscle cells which is accomplished by accumulation of cellular and extracellular lipid, collagen and proteoglycans. Disruption of endothelial barrier may follow any form of injury be it mechanical or immunological. ${ }^{15,16}$

Prevalence of diabetes is greater in persons over age of 50 Years. In our study of 50 patients ranging from 21 to 90 years, it was found that age group 51-60 years had the highest number of patients 17 (34\%). In comparison to the study done by Jennifer A Mayfield et al, the present study had more number of male patients (70\%) suffering from diabetic foot lesions than females (30\%). But the proportion between the two was far greater in this study. The present study had ratio of $\mathrm{M}: \mathrm{F}$ as $2.33: 1$ whereas in a study done by Jennifer A Mayfield, the M: F ratio was found to be almost equal. ${ }^{17}$

Higher incidence in males may be due to associated habits of smoking, alcoholism, type of work etc. In the present study, trauma as a causative factor is more common as compare to other studies. The reason may be due to most of the patients were bare foot walkers and usage of slippers. According to Jennifer A Mayfiled et al study about $3 / 4^{\text {th }}$ of total patients with diabetic foot lesion had duration of diabetes for more than 16 years which did not correlate with present study where patients with diabetic foot lesions had diabetes duration of less than 10 years in about $82 \%$ of the cases. ${ }^{17}$

In present study, patients with diabetic duration more than 5 years were more prone for complications. The severity of the disease depends upon not the age of patient but on the diabetic age. Most of the patients presented with more than one lesion. Only major lesions are considered above. Ulcer was major lesion seen here which was present in 19 (38\%) patients while gangrene seen in $7(14 \%)$ patients was the least common lesion. In this study, absence of dorsalispedis pulse was seen in $20(40 \%)$ patients. Other peripheral pulses like posterior tibial absent in $15(30 \%)$ patients. Popliteal pulse was absent in 4(8\%) patients. Dorsalispedis was found absent in a study done by Edmunds et al $31.4 \%$ and also in a study conducted by Ali SM et al 56\% and in present study, it was found to be $40 \% .{ }^{18,19}$

The absence of dorsalispedis pulses is variable in the above studies. It may be due to vasculopathy, cellulites with edema and anatomical variations of dorsalispedis artery. In a study commonest presentation was grade III. This is because of lack of knowledge about health care literacy making patients presenting late and failing early detection. Among 50 patients studied with peripheral vascular insufficiency 41 $(82 \%)$ patients had atherosclerotic plaque suggesting that significant number of patients had peripheral arterial disease. Out of 41 plaque patients 8 patients had significant stenosis i.e. $50-99 \%$ occlusion 29 patients had $1-49 \%$ stenosis. Out of 50 patients studied, $4(8 \%)$ patients had complete occlusion. Duplex Doppler imaging is safe, cost effective, repeatable, non-invasive procedure for investigating lower limb arteries. Hence, it is the primary investigation of choice in all cases of lower extremity arterial disease and helps to decide the need for further evaluation by angiography.

Duplex sonography allows the evaluation and quantification of arterial disease. Colour Doppler study also helps in the 
follow-up of the arterial diseases. This study showed that these patients had risk factors for PVD. The use of Doppler will aid early diagnosis of critical limb at risk of loss and help prevent and reduce high rate of limb loss among patients.

\section{CONCLUSION}

The findings of this study suggested vascular insufficiency in $62 \%$ of the patients with dorsalispaedis being the commonest site of involvement. The insufficiency was moderate and the flow was biphasic in a majority of the cases. The mean duration of disease was almost a decade in patients exhibiting Doppler-documented vasculopathy. Hence, colour Doppler sonography can accurately locate the site and extent of stenosis/occlusion.

\section{REFERENCES}

1. Nighat N, Khan IA, Qadri MH, Sher SA. Myths about diabetes mellitus among non-diabetic individuals attending primary health care centres of Karachi suburbs. J Coll Physicians Surg Pak 2007; 17(1):398401.

2. Ravichandran Kailasam Subramaniam. Assessment of risk factors for patients suffering from Diabetic foot ulcer. International Journal of Contemporary Medical Research 2018; 5(2):B11-B13.

3. Marso SP, Hiatt WR. Peripheral arterial disease in patients with diabetes. J Am Coll Cardiol 2006; 47(5):921-9.

4. Hittel N, Donnelly R. Treating peripheral arterial disease in patients with diabetes. Diabetes Obes Metabol 2002; 4:S26-31.

5. Selvam Prasannabalaji, Govindarajan Ashok Swaminathan, Subramaniam Sethupathy. Oxidative stress and antioxidant status before and after grafting in diabetic patients with foot ulcer. International Journal of Contemporary Medical Research 2018; 5(10):J1-J4.

6. Koelemay MJ, Legemate DA, de Vos H, van Gurp AJ, Balm R, Reekers JA, et al. Duplex scanning allows selective use of arteriography in the management of patients with severe lower limb arterial disease. J Vase Surg 2001; 34(2):661-7.

7. Ankur Kumar, A. K. Agrawal, Manoj Kumar, Ashok Kumar Sharma, Pinki Kumari. Aerobic bacterial profile of diabetic foot and its antibiogram in RIMS, Ranchi - a tertiary care hospital. International Journal of Contemporary Medical Research 2017;4(1):251-253.

8. Shared Pendsey: Practical management of diabetes: Jaypee Brother Medical Publication. $2^{\text {nd }}$ edition, New Delhi, India 1-230; 2003.

9. Oakley Wilfried, Catterall RC, Martin MM et al: Etiology and management of lesions of the feet in diabetes mellitus. British Medical Journal 1986; 27(6):953-957.

10. Green DA: Sorbitol, Phosphoinsotides and Na-KATpase in pathogenesis of diabetic complication. New England Journal of Medicine 1987; 316(2):599-606.

11. Bagdade JD, Root RK, Bulger RJ: Impaired leucocyte function in patients with poorly controlled diabetes: Diabetes 1978; 27(4):889-894.

12. Giurini JM, Polasky J: Evolution: The diabetic foot: Medical and surgical management by Veves A et al: 3rd
Edition: Humana Press, Totowa, New Jersy, USA 2012; 185-201.

13. Mayfield JA, Reiber GF, Nelson RG, Green T: A foot risk classification System to predict diabetic amputation in diabetic foot: Diabetes Care 1996; 34(5):704-709.

14. Lavery LA, Armstrong DG, Wunderlich RP, et al: Risk Factors for foot infection in individual with diabetes. Diabetes Care 2006; 29(1):1288-1393.

15. Boyko EJ, Abrioni JH, Stensel V, et al: A prospective study of risk factors for diabetic foot ulcer. The Seattle Diabetic foot study. Diabetes Care 1999; 22(3):1036-42.

16. Crisband, Lamm DL, Grossman HB, Smith J, Sullivan J: Basement Membrane collagen disease in diabetes: Journal of Biochemistry and Biophysics 1980; 95(1):765-770.

17. Calhoun JH, Cantrell J, Cobos J, et al: Treatment of diabetic foot infection: Wagner Classification, Therapy and outcome. Journal of foot and ankle surgery 1988; 9(6):101-106.

18. Edmunds ME. Progress in care of the diabetic foot. Lancet 1999; 354:270-2.

19. Ali SM, Basit A, Sheikh T, Mumtaz S, Hydrie MZ. Diabetic foot ulcer - a prospective study. J Pak Med Assoc 2001; 51(2):78-81.

Source of Support: Nil; Conflict of Interest: None

Submitted: 30-09-2019; Accepted: 29-10-2019; Published online: 24-11-2019 